\title{
Health Care Contacts in the Year Before Suicide Death
}

\author{
Brian K. Ahmedani, $P h D^{7}$, Gregory E. Simon, MD², Christine Stewart, $P h D^{2}$, Arne Beck, PhD ${ }^{3}$, \\ Beth E. Waitzfelder, PhD" , Rebecca Rossom, MD ${ }^{5}$, Frances Lynch, PhD ${ }^{6}$, Ashli Owen-Smith, PhD”, \\ Enid M. Hunkeler, $M A^{8}$, Ursula Whiteside, $P h D^{2}$, Belinda H. Operskalski, MPH², \\ M. Justin Coffey, $M D^{9}$, and Leif I. Solberg, $M D^{5}$
}

\begin{abstract}
'Center for Health Policy and Health Services Research, Henry Ford Health System, Detroit, MI, USA; ${ }^{2}$ Group Health Cooperative, Group Health Research Institute, Seattle, WA, USA; ${ }^{3}$ Kaiser Permanente Colorado, Institute for Health Research, Denver, CO, USA; ${ }^{4}$ Kaiser Permanente Hawaii, Center for Health Research, Honolulu, HI, USA; ${ }^{5}$ HealthPartners, Institute for Education and Research, Minneapolis, MN, USA; ${ }^{6}$ Kaiser Permanente Northwest, Center for Health Research, Portland, OR, USA; ${ }^{7}$ Kaiser Permanente Georgia, Center for Health Research, Atlanta, GA, USA; ${ }^{8}$ Kaiser Permanente Northern California, Division of Research, Oakland, CA, USA; ${ }^{9}$ Department of Psychiatry, Henry Ford Health System, Detroit, MI, USA.
\end{abstract}

BACKGROUND: Suicide prevention is a public health priority, but no data on the health care individuals receive prior to death are available from large representative United States population samples.

OBJECTIVE: To investigate variation in the types and timing of health services received in the year prior to suicide, and determine whether a mental health condition was diagnosed.

DESIGN: Longitudinal study from 2000 to 2010 within eight Mental Health Research Network health care systems serving eight states.

PARTICIPANTS: In all, 5,894 individuals who died by suicide, and were health plan members in the year before death.

MAIN MEASURES: Health system contacts in the year before death. Medical record, insurance claim, and mortality records were linked via the Virtual Data Warehouse, a federated data system at each site.

KEY RESULTS: Nearly all individuals received health care in the year prior to death (83\%), but half did not have a mental health diagnosis. Only $24 \%$ had a mental health diagnosis in the 4-week period prior to death. Medical specialty and primary care visits without a mental health diagnosis were the most common visit types. The individuals more likely to make a visit in the year prior to death $(p<0.05)$ tended to be women, individuals of older age (65+ years), those where the neighborhood income was over \$40,000 and $25 \%$ were college graduates, and those who died by non-violent means.

CONCLUSIONS: This study indicates that opportunities for suicide prevention exist in primary care and medical settings, where most individuals receive services prior to death. Efforts may target improved identification of mental illness and suicidal ideation, as a large proportion may remain undiagnosed at death.

Received June 24, 2013

Revised August 23, 2013

Accepted December 20, 2013

Published online February 25, 2014
KEY WORDS: suicide; health services research; prevention; mental health; primary care.

J Gen Intern Med 29(6):870-7

DOI: $10.1007 / \mathrm{s} 11606-014-2767-3$

(c) Society of General Internal Medicine 2014

\section{INTRODUCTION}

Suicide prevention is a public health priority. Suicide is the tenth leading cause of death in the US, and the number one cause of injury-related death-recently surpassing mortality due to motor vehicle traffic accidents. ${ }^{1,2}$ Suicide accounts for the loss of nearly 37,000 American lives each year according to the Centers for Disease Control and Prevention, ${ }^{1}$ and there is evidence that the suicide rate has not improved over time. ${ }^{3,4}$ However, research suggests that suicide is potentially preventable. ${ }^{5-7}$ This research, and growing national concern, led to the development of a national strategy for suicide prevention. ${ }^{5}$

A joint report published in 2012 by the United States (US) Surgeon General and the National Action Alliance for Suicide Prevention (NAASP) outlined a set of ambitious goals and objectives to reduce suicide in the US. ${ }^{5}$ As part of this strategy, the research task force is working with the National Institute of Mental Health on a specific research agenda to reduce suicide mortality by $20 \%$ in the next 5 years. 5,8

For suicide prevention efforts to be effective, accurate identification of those at risk is required. Unfortunately, this has been difficult. A limited evidence base to inform suicide prevention has made it hard to design, implement, and target interventions for those at greatest risk. ${ }^{9}$ The US Preventive Services Task Force has stated that there is not enough information available to recommend screening for suicide in primary care. ${ }^{10,11}$

Previous research indicates that many individuals utilize health services, particularly in primary care, prior to suicide. ${ }^{12,13}$ For example, Ilgen et al. found that over half 
of male veterans with substance use disorders used Veterans Health Administration services in the year before death, with most visits occurring in general medical settings. ${ }^{14}$ Nonetheless, this study and others have either been conducted outside of the US or have relied on small or non-representative samples. ${ }^{14-23}$ Analogous data are not available for the US general population. Understanding utilization patterns and where to target prevention efforts is limited. This information is sorely needed to optimize the identification of those at greatest risk for suicide and to help suicide prevention efforts be more successful. With this information we may achieve the national goal of reducing suicide by $20 \%$ in 5 years.

The current study used data from a large and representative population in the US to examine use of health care in the year prior to suicide death. The following questions were addressed:

1) What proportion of people dying by suicide received specific types of health services at various times in the year prior to death?

2) In what proportion of encounters were mental health conditions identified?

3) How did patterns of service use vary by age, sex, type of health insurance, indicators of socioeconomic status, and mode of death?

\section{METHODS}

The Mental Health Research Network (MHRN) is a consortium of 11 health care systems with affiliated health maintenance organizations (HMO). These systems are part of the HMO Research Network (HMORN), which includes 18 US-based health systems. The MHRN health systems serve over 11 million individuals across 11 states with diverse populations.

The current study involved eight MHRN health systems, each of which is primarily located in a different state. These sites included: Group Health Cooperative (Washington), HealthPartners (Minnesota), and Henry Ford Health System (Michigan), as well as Kaiser Permanente systems in Colorado, Georgia, Hawaii, Northern California, and Oregon. Institutional Review Boards at each site approved this project.

All HMORN sites maintain a Virtual Data Warehouse (VDW) consisting of electronic medical record (EMR) and insurance claim data for their enrolled members. ${ }^{24,25}$ Data on encounters, pharmacy fills, diagnoses, medical tests, and demographics are organized using the same definitions across sites and are quality checked locally. These data are matched to official regional mortality records using Social Security Numbers or patient names, birthdates, and demographic profiles.
In the current study, data were extracted from the VDW on all suicide deaths using International Classification of Diseases, 10th revision (ICD-10) codes ranging from X60 to $\mathrm{X} 84{ }^{26}$ These codes were stratified into violent (X70X84), and non-violent (X60-X69, X84) causes. There were 5,894 suicides captured across all sites from 2000-2010. This sample accounts for $1.6 \%$ of the 367,403 total suicides that occurred in the United States during the same period (http://www.cdc.gov/nchs/deaths.htm).

VDW data were extracted for all visits for each individual in the year prior to death. These data were categorized into subgroups of utilization by outpatient, inpatient, and emergency visits, as well as primary care, specialty chemical dependency mental health services, and medical specialty services. International Classification of Diseases, 9th revision (ICD-9) codes were linked with health system encounters, which allowed the categorization of visits by diagnosis. ${ }^{27}$ ICD-9 codes were grouped as follows: mental health (293-302.9 or 306.0-316), chemical dependency (291-292.9 or 303.0-305.9), and other.

Demographic information on age, sex, and insurance were available from the VDW. For each person, estimated neighborhood income and education were calculated using patient addresses and census block data. Race/ethnicity data were not available for several sites prior to 2008; thus, this variable was not included. Preliminary data comparisons across sites were made to investigate possible variation and to ensure data accuracy before creating aggregated estimates. This comparison found very little site variation in the patterns of service contacts prior to suicide and in the rates of psychiatric diagnosis, supporting the stability of the aggregated estimates. These data are available upon request.

Statistical analyses began with aggregated descriptive characteristics of suicides stratified by study covariates. A cumulative utilization curve was generated to examine weekly use of health services in the year prior to death, by utilization category. Chi-square tests were used to compare utilization in total and by category, within 4 and 52 weeks prior to death, by the main covariates. For the 4week analysis, HMO enrollment interval was used as the denominator. Thus, those who were not members of the HMO during that 4 -week period were not included. The 52week analysis used total deaths as the denominator, since all individuals were enrolled in the HMO for a portion of the year.

\section{RESULTS}

As shown in Table 1, there were 5,894 suicides identified from 2000-2010. These individuals were enrolled in the health plan during the year before suicide. Enrollment was over $83 \%$ during each weekly interval throughout the study. The largest number of suicides occurred among men 
Table 1. Sample Characteristics of Individuals Who Died by Suicide, 2000-2010

\begin{tabular}{ll}
\hline \hline & Suicide deaths n (\%) \\
\hline Total & 5,894 \\
Age & $349(5.9 \%)$ \\
$0-19$ years & $1,565(26.6 \%)$ \\
$20-39$ years & $2,746(46.6 \%)$ \\
$40-64$ years & $1,234(20.9 \%)$ \\
$65+$ years & \\
Sex & $4,534(76.9 \%)$ \\
Male & $1,359(23.1 \%)$ \\
Female & $3,991(67.7 \%)$ \\
Insurance type & $131(2.2 \%)$ \\
Commercial & $1,215(20.6 \%)$ \\
Medicaid & $209(3.6 \%)$ \\
Medicare & $348(5.9 \%)$ \\
Self-pay & $1,806(30.6 \%)$ \\
Other & $4,088(69.4 \%)$ \\
Neighborhood income & \\
$\quad<40,000$ per year & \\
$\geq \$ 40,000$ per year & $3,002(50.9 \%)$ \\
Neighborhood education & $2,892(40.1 \%)$ \\
$<25 \%$ college grad & \\
$\geq 25 \%$ college grad & $4,664(79.1 \%)$ \\
Mode of death & $1,230(20.9 \%)$ \\
Violent &
\end{tabular}

$(n=4,534,77 \%)$ and individuals aged $40-64$ years $(n=$ $2,746,47 \%$ ), those with a neighborhood annual income of at least $\$ 40,000(n=4,088,69 \%)$, a neighborhood education completion level of less than $25 \%$ college graduates $(n=3,002,51 \%)$, and commercial insurance $(n=$ $3,991,68 \%)$. Individuals most often died by violent $(n=$ 4,664, $79 \%$ ) means. The proportion of total suicides by cause was as follows: 1) Violent-Firearm (48.6 \%), Hanging (22.0 \%), Jumping (3.6 \%), Sharp/Blunt Object $(2.0 \%)$, Drowning $(1.6 \%)$, Other $(1.5 \%)$; and 2$)$ NonViolent-Self-poisoning (20.2\%), Other (0.6\%).

The cumulative utilization curve shown in Figure 1 depicts the aggregated rates of weekly health care utilization, by type, for the year prior to death. Approximately
$22 \%(n=1,311)$ of individuals used any services in the week before death. Less than $10 \%$ used any specific type of service during this period. Primary care and medical specialty visits without a mental health diagnosis were most common in the month prior to death. From four to twelve months prior to death, primary care visits without a mental health diagnosis were most common.

Nearly $50 \%(n=2,844)$ of enrolled HMO members $(n=$ 4,988 or $85 \%$ of total deaths) made a health care visit within 4 weeks of death (Table 2). Women (59\%), older adults (65+ years old, $67 \%$ ), and those who died by nonviolent means (54\%) were most likely to make a visit during this period $(p<0.05)$. Individuals with a census block-estimated education of at least $25 \%$ college graduates $(51 \%)$ and annual income of at least $\$ 40,000$ $(52 \%)$ were more likely to make any visit $(p<0.05)$. Only $24 \%(n=1,189)$ had a visit coded with a mental health diagnosis in the 4-week period prior to death. The types of utilization most prevalent during this period were medical specialty $(n=1,201,25 \%)$ and primary care visits $(n=$ $1,047,21 \%$ ) without mental health diagnosis.

In Table 3, $83 \%(n=4,873)$ used any health services in the year before death, with approximately $45 \%(n=2,662)$ of individuals receiving a mental health diagnosis. In the year before death, most individuals made primary care $(n=$ $3,780,64 \%)$ and medical specialty visits $(n=3,543,62 \%)$, but did not receive a mental health diagnosis. Both of these visit types were substantially more common than emergency visits without a mental health diagnosis $(n=2,130,36 \%)$ and outpatient mental health specialty visits $(n=1,722$, $29 \%$ ), which were the next most common types. For each visit type (inpatient, outpatient, emergency, primary care), at least half did not include a mental health or chemical dependency diagnosis. Similar to the 4-week interval, visits were most common among those representing the following categories $(p<0.05)$ : women (89\%), older adults $(95 \%)$,
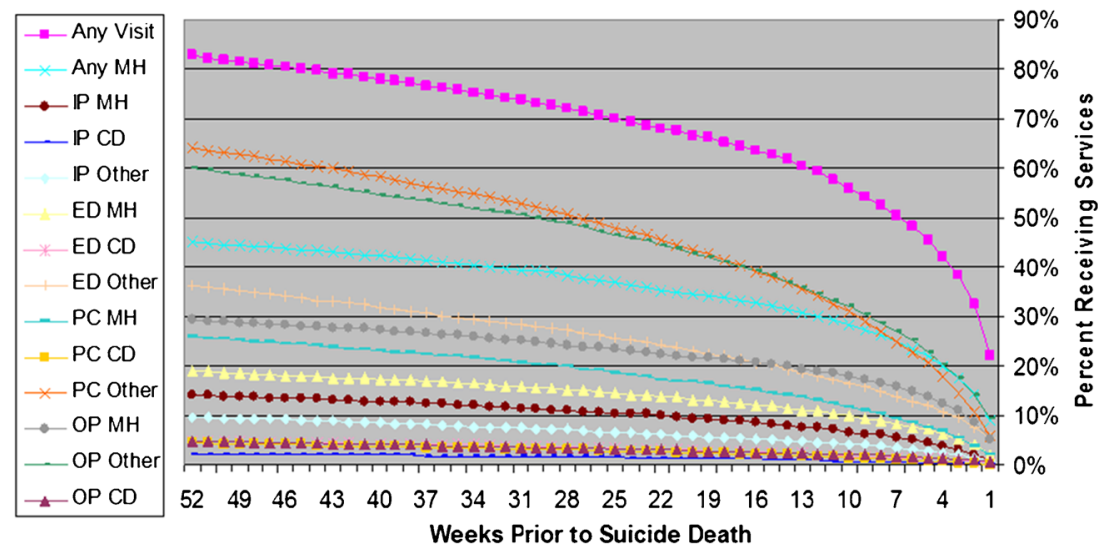

Figure 1. Cumulative weekly percentage of individuals receiving health services in the year prior to suicide death, by visit type. $M H$ denotes a visit with a Mental Health diagnosis; $C D$ a visit with a Chemical Dependency diagnosis; $I P$ an Inpatient stay; $E D$ an Emergency

Department visit; $O P$ an Outpatient visit; $P C$ a Primary Care visit; 'Other' includes all visits without an attached mental health or chemical dependency diagnosis code. 


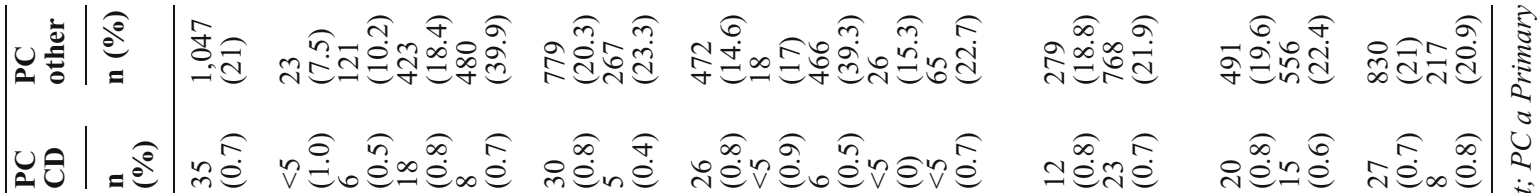

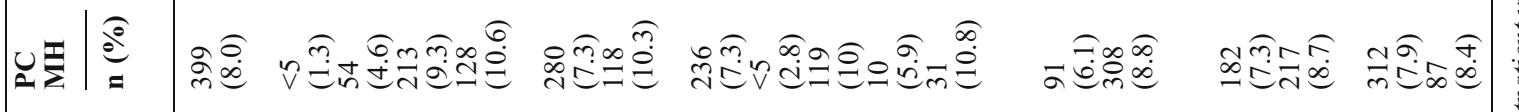

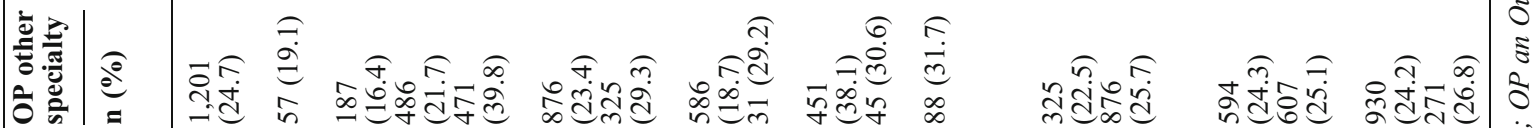

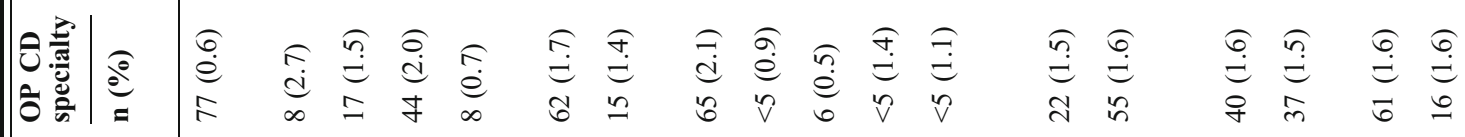

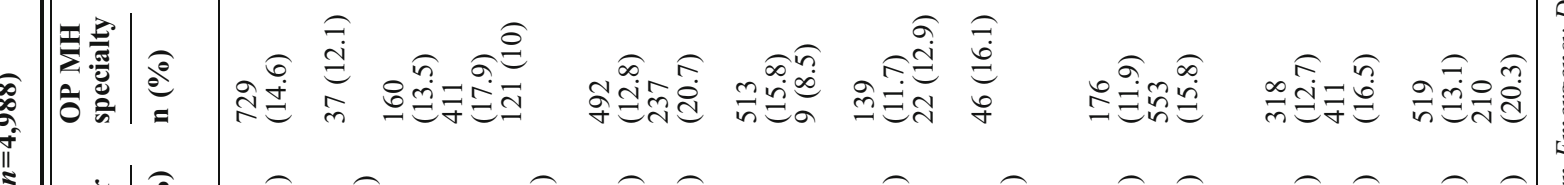

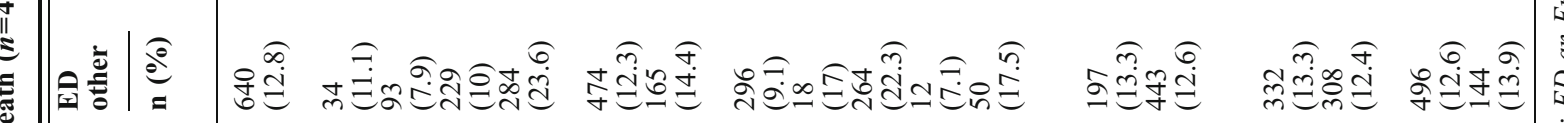

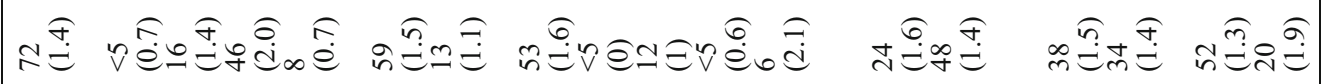

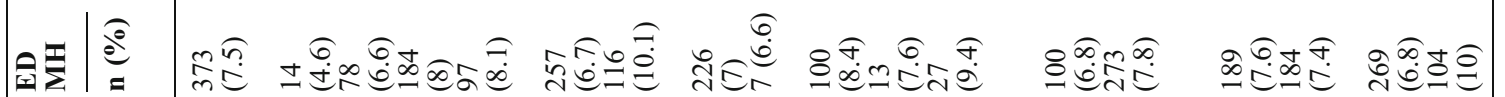

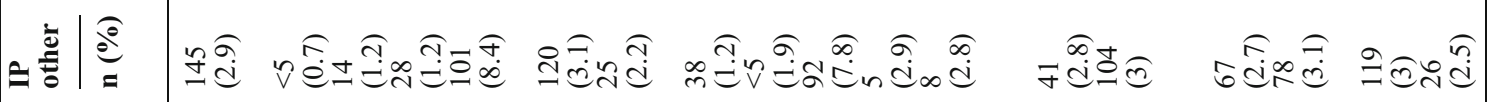

|ق $\mid$ a

$|\equiv|$ =

$\overrightarrow{\tilde{s}}$

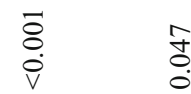

훙

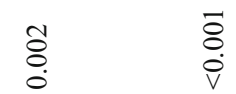

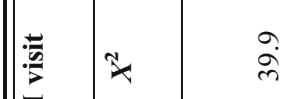

aे

$\stackrel{0}{0} \quad \stackrel{0}{0}$

$\stackrel{0}{6}$

$\stackrel{\circ}{\circ} \quad \stackrel{\ominus}{\forall}$

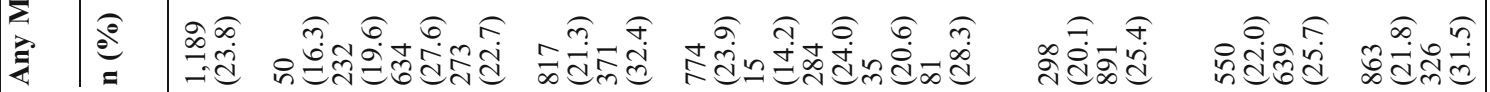

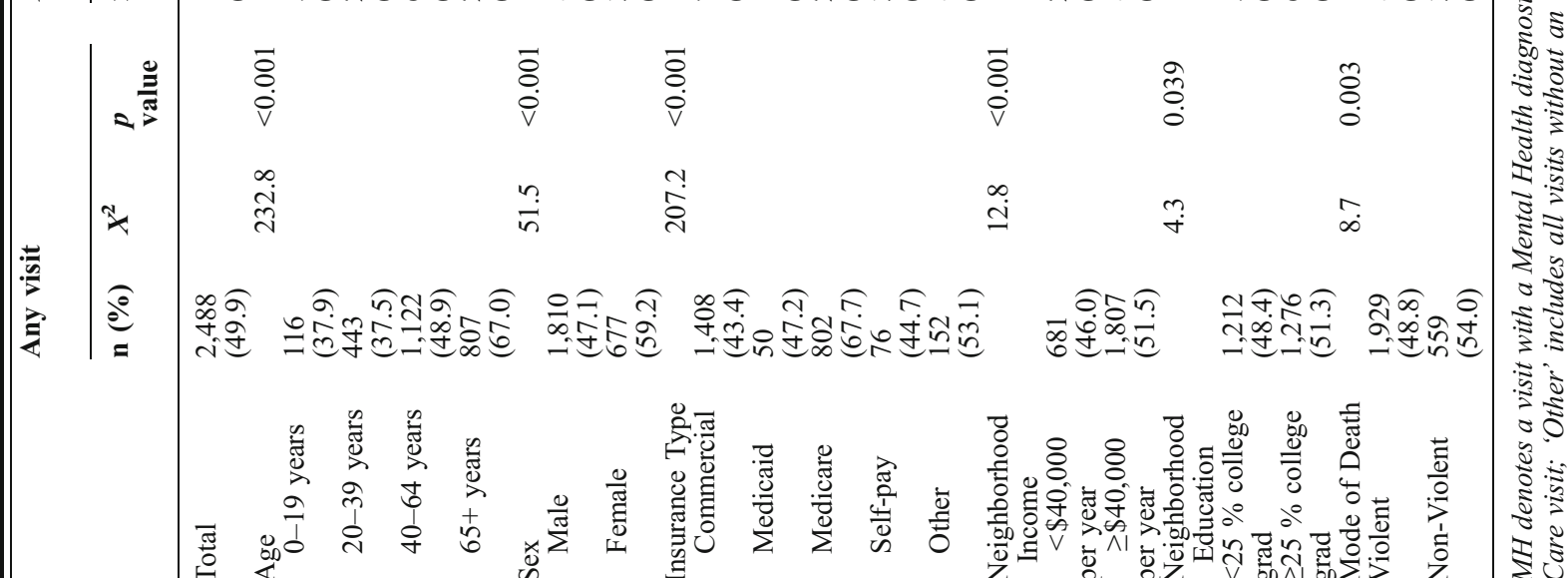


and those who lived in neighborhoods with higher estimated education (84\%) and income levels (84\%). Again, visits were more common by those who died by non-violent means (89\%). The oldest age groups made primary care visits more frequently than the younger groups ( $\leq 19$ year $=40 \% ; \geq 65$ year $=87 \%$ ), but those under 65 were more frequent users of outpatient mental health care.

\section{DISCUSSION}

Using data from the largest geographically diverse sample of US general population members to date, this study shows that the majority of those who died by suicide received health services in the year prior to death and half made a medical visit within 4 weeks. The relative frequency of visits differed markedly by sex and age, with women and older adults most likely to have medical encounters. Our findings are consistent with a systematic review, which found that, on average, $45 \%$ of individuals had contact with primary care within a month before suicide, and visits were more common among older adults. ${ }^{12}$ This study and others point to the importance of outreach efforts, especially to men and younger/middle age groups, while taking advantage of existing visits to identify risk. ${ }^{28}$

The results have other important implications for targeting suicide prevention. While the highest risk for suicide is following a psychiatric hospitalization, ${ }^{29}$ the attributable risk is smaller since few individuals have a psychiatric hospitalization before death. More than $85 \%$ of individuals who died by suicide did not have this experience, and only $5 \%$ within 4 weeks of death. Alternatively, over $60 \%$ of individuals made primary care and medical specialty visits without mental health diagnosis in the year before death (over $20 \%$ for each within 4 weeks of death). Since most individuals ordinarily make these types of visits, the risk of suicide may be lower among this group of service users. However, in order to reach the largest number of health service users before suicide, prevention efforts need to extend into primary care and other medical specialty departments.

While prevention models have been developed since the 1990 s, they have not been widely adopted in primary care. ${ }^{6,13,30}$ There is more promise for future success, though, as health systems implement comprehensive EMRs. ${ }^{31}$ Using EMRs, providers can be prompted to screen for suicide and can be alerted regarding possible risk. Instead of completing patient history paper forms in waiting rooms, patients can also access their record online or be asked to use a kiosk in the waiting area to complete screening before appointments, thus increasing screening rates. This information is presented via the EMR to providers prior to and during each visit to aid with diagnosis, treatment decisions, and tracking outcomes. ${ }^{32}$
Using available screening and clinical data, the EMR can automatically calculate which individuals are most at risk and provide clinical decision support. EMRs can be shared across providers and networks, improving opportunities for care coordination. ${ }^{33}$ EMRs are useful to provide treatment engagement information. They can link to pharmacy fill records to inform providers about whether patients have filled prescribed medications. ${ }^{34}$ Using appointment scheduling systems within the EMR, providers can determine whether patients are attending psychotherapy or other follow-up appointments. EMRs are being implemented all over the health care industry to meet requirements for the Affordable Care Act and other federal policies. ${ }^{35}$ EMR systems are already in use at all of the health systems in this study.

Suicide assessment was also listed as a 2011 National Patient Safety Goal by the Joint Commission, thus making it a priority for accredited hospitals. ${ }^{35}$ Screening in primary care has shown effectiveness for risk detection, but there is a dire need to improve screening rates. ${ }^{6}$ The Columbia Suicide Severity Rating Scale or the ninth item of the Patient Health Questionnaire (PHQ-9) are easy-to-use, brief, and effective measures for identification. They can be administered by a nurse or medical assistant in the office. $^{36,37}$ Positive suicide screens can initiate conversations about suicidality between the health provider and patient, and should prompt psychiatric evaluation and follow-up. ${ }^{38}$

Another important finding from this study is that a mental health diagnosis was absent in over half of all individuals in the year before death and approximately $75 \%$ in the 4 weeks before death. Mental health diagnosis was even less common among disadvantaged groups with lower levels of education and income. Furthermore, over three-fifths of individuals had a primary care or medical specialty visit without a mental health diagnosis in the year before death. We were not able to determine whether a mental health condition was detectable and not recognized at these visits, if one was recognized and not documented, or if one arose during the time after the visit. Since psychological autopsy studies demonstrate that over $90 \%$ of those who die by suicide have mental health problems, ${ }^{39}$ it suggests that many individuals were afflicted at death, but their conditions were not documented. This is not surprising, as estimates suggest that it takes a median of 8 years between the onset of mental health conditions and receipt of first treatment. ${ }^{40}$ Future research may examine medical chart notes for any signs of undiagnosed mental health concerns.

These findings do indicate that mental health and suicide risk may need to be assessed more thoroughly, especially in general medical settings. By detecting mental health more effectively, we may be able to begin treatment earlier and prevent many suicides. The first step of this process is underway at many health systems. They have begun to integrate mental health services into primary care using screening instruments for depression and alcohol and drug 


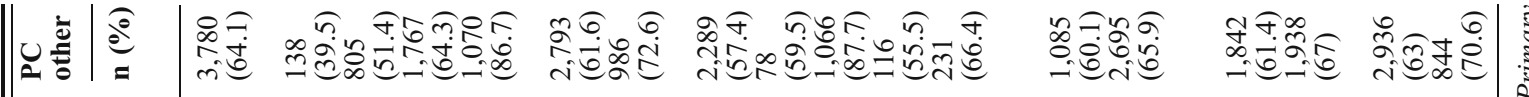

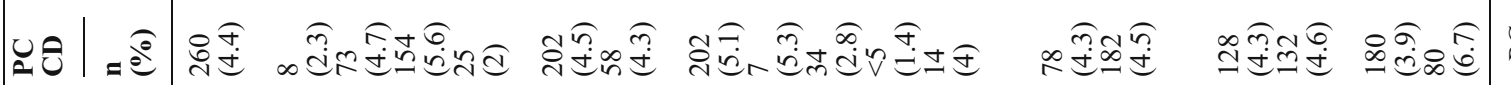

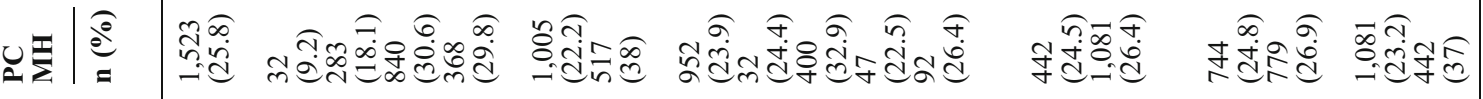

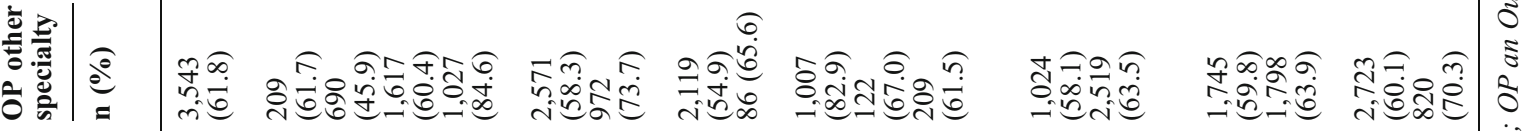

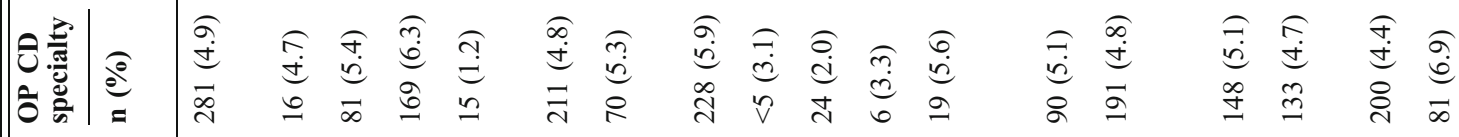

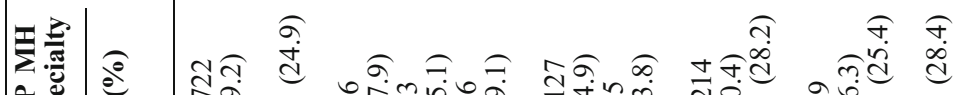

$$
\stackrel{\overrightarrow{8}}{\dot{0}}
$$

$\bar{\circ} \quad \overline{0}$

s.

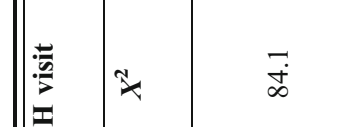

$\stackrel{+}{\stackrel{2}{\Xi}}$

$\stackrel{\ddots}{\because} \stackrel{\sim}{=}$

$\stackrel{\check{c}}{\stackrel{2}{2}}$

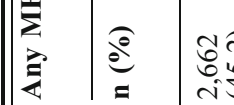

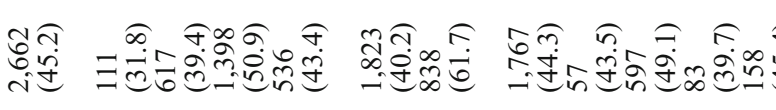

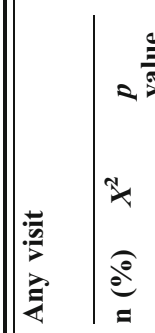

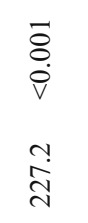

$\begin{array}{ll}\overline{8} & \overline{8} \\ \dot{\nabla} & \dot{v}\end{array}$

in $\stackrel{m}{\text { in }}$

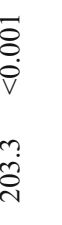

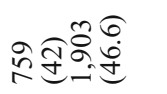

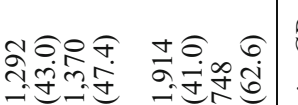

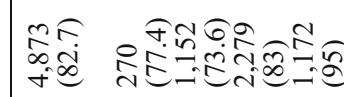

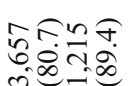

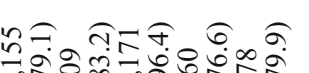

$\stackrel{9}{=}$

$\stackrel{2}{\Upsilon}$

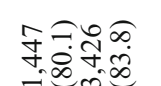

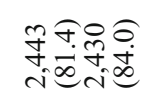

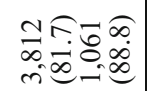

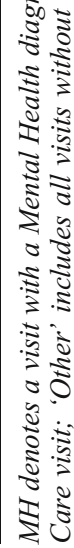


use, followed by brief interventions and/or risk stratified care. $^{41-43}$ However, mental health screening is not common across all systems or providers. ${ }^{44}$ It is important to note that the US Preventive Services Task Force (USPSTF) recommends screening for depression only when a system is in place to provide effective care for those identified. ${ }^{45}$ Those providers who do not meet this recommendation should consider developing a system to address mental health concerns. This process may be among the greatest challenges to optimizing suicide prevention efforts. Mental health services systems may be modeled after those developed by While et al., Coffey, and Knox et al. ${ }^{28,46,47}$ Each of these systems demonstrated reductions in suicide rates after implementing mental health and suicide prevention strategies. Hallmark characteristics of these systems include using assessment and clinical information to provide clinical decision support, using suicide surveillance systems, integrated care across providers, improved access to care, and a culture in which providers are committed to suicide prevention.

More effort may be needed to train and support providers on the identification of suicide and treatment of mental health. A recent study found that a substantial number of primary care physicians would not screen for suicide even if they suspected that a person met criteria for depression. ${ }^{48}$ One problem may be the low level of competence and training in suicidality that medical providers report. ${ }^{49}$ Nonetheless, research shows that physicians who receive training feel more competent working with individuals at risk for suicide and are more likely to screen for and treat suicidality. ${ }^{49,50}$ Training should include information on use of screening tools and appropriate processes for positive screens, including the best care pathways given the level of risk. Other factors that limit expanded suicide assessment include the complexity of patients' symptoms and conditions, competing demands for providers, and lack of engagement in treatment among patients. ${ }^{51}$ More research is needed to optimize health care processes and workflows to mitigate these barriers.

This study has limitations. First, race/ethnicity was not investigated, since many sites did not collect self-reported race/ethnicity data until 2008. Second, all individuals were not enrolled in the health plan for the entire 12 months prior to death. Utilization that occurred outside of the system during a non-enrolled period was missed. Nonetheless, enrollment was over $83 \%$ for each weekly interval. Future research may compare data from this sample to those who did not die by suicide. Third, mental health concerns may have been assessed during some visits, but a diagnosis was not documented. While there was little variation in diagnoses across sites, rates may vary in other locations. Fourth, while our sample is large, it represents $\sim 1.6 \%$ of all suicides that occurred in the United States during the same period and does not represent geographic areas not in the sample. Furthermore, all individuals in this study had health insurance (commercial, Medicaid, or Medicare), and were patients in well-resourced health systems. Our findings may not represent those who are uninsured. Nonetheless, our data showed remarkable consistency across sites, strengthening generalizability. Finally, suicides may have been under-reported, as they are coded conservatively in official records. ${ }^{52,53}$

In conclusion, this is the largest investigation of suicide and health services utilization to date, across eight states, with consistent and therefore generalizable results. As such, this study provides important information to help target future prevention in order to achieve the goals set forth in the joint 2012 national strategy report. A large proportion of individuals have health system contact in the year before suicide, but a mental health diagnosis is often not documented. Thus, greater efforts should be made to assess mental health and suicide risk. Most visits occur in primary care or medical specialty settings, and suicide prevention in these clinics would likely reach the largest number of individuals.

Acknowledgements: This project was supported by Award Number U19MH092201 from the National Institute of Mental Health. The content is solely the responsibility of the authors and does not necessarily represent the official views of the National Institute of Mental Health or the National Institutes of Health. Drs. Ahmedani and Simon had full access to all of the data and take responsibility for the integrity of the data and accuracy of the data analysis. All authors have contributed to and have approved the final submitted manuscript. The authors would like to thank all members of the HMO and Mental Health Research Networks, whose contributions to building the Virtual Data Warehouse and to the integrity of the data have made this study possible.

Conflicts of Interest: The authors declare that they do not have a conflict of interest.

Corresponding Author: Brian K. Ahmedani, PhD; Center for Health Policy and Health Services Research, Henry Ford Health System, 1 Ford Place, 3A, Detroit, MI 48202, USA (email: bahmeda1@hfhs.org).

\section{REFERENCES}

1. Heron M. Deaths: Leading causes for 2009. Natl Vital Stat Rep. 2012;61(7): 1-94.

2. Rockett IR, Regier MD, Kapusta ND, Coben JH, Miller TR, Hanzlick $\mathbf{R L}$, et al. Leading Causes of Unintentional and Intentional Injury Mortality: United States, 2000-2009. Am J Public Health. 2012;102(11):e84-92.

3. Crosby AE, Ortega L, Stevens MR. Suicides - United States, 19992007. MMWR Surveill. Summ. 2011;60:56-9.

4. Holinger PC, Klemen EH. Violent deaths in the United States, 19001975. Relationships between suicide, homicide and accidental deaths. Soc Sci Med. 1982;16(22):1929-38.

5. United States Department of Health and Human Services Office of the Surgeon General and National Action Alliance for Suicide Prevention. 2012 National Strategy for Suicide Prevention: Goals and Objectives for Action. Washington, D.C. 2012.

6. Mann JJ, Apter A, Bertolote J, Beautrais A, Currier D, Haas A, et al. Suicide prevention strategies: a systematic review. JAMA. 2005;294(16):2064-74.

7. Ahmedani BK, Perron BE, Ilgen MA, Abdon A, Vaughn MG, Epperson MW. Suicide thoughts and attempts and psychiatric treatment utilization: Informing prevention strategies. Psychiatr Serv. 2012;63(2):186-9. 
8. Insel T. Strategy on suicide prevention. http://www.nimh.nih.gov/ about/director/2012/strategy-on-suicide-prevention.shtml; 2012.

9. Gaynes BN, West SL, Ford CA, Frame P, Klein J, Lohr KN. Screening for suicide risk in adults: a summary of the evidence for the U.S. Preventive Services Task Force. Ann Intern Med. 2004;140(10):822-35.

10. United States Preventive Services Task Force. Screening for suicide risk. http://www.uspreventiveservicestaskforce.org/3rduspstf/suicide/ suiciderr.htm; 2004.

11. O'Connor E, Gaynes BN, Burda BU, Soh C, Whitlock EP. Screening for and Treatment of Suicide Risk Relevant to Primary Care: A Systematic Review for the U.S. Preventive Services Task Force. Ann Intern Med. 2013.

12. Luoma JB, Martin CE, Pearson JL. Contact with mental health and primary care providers before suicide: a review of the evidence. Am J Psychiatry. 2002;159(6):909-16.

13. Bruce ML, Pearson JL. Designing an intervention to prevent suicide: PROSPECT (Prevention of Suicide in Primary Care Elderly: Collaborative Trial). Dialogues Clin Neurosci. 1999;1(2):100-12.

14. Ilgen MA, Conner KR, Roeder KM, Blow FC, Austin K, Valenstein M. Patterns of treatment utilization before suicide among male veterans with substance use disorders. Am J Public Health. 2012;102(Suppl 1):S88-92.

15. Da Cruz D, Pearson A, Saini P, Miles C, While D, Swinson N, et al. Emergency department contact prior to suicide in mental health patients. Emerg Med J. 2011;28(6):467-71.

16. Simon GE, VonKorff M. Suicide mortality among patients treated for depression in an insured population. Am J Epidemiol. 1998;147(2):155-60.

17. Cho J, Kang DR, Moon KT, Suh M, Ha KH, Kim C, et al. Age and gender differences in medical care utilization prior to suicide. J Affect Disord. 2012.

18. Basham C, Denneson LM, Millet L, Shen X, Duckart J, Dobscha SK. Characteristics and VA health care utilization of U.S. Veterans who completed suicide in Oregon between 2000 and 2005. Suicide Life Threat Behav. 2011;41(3):287-96

19. Bell NS, Harford TC, Amoroso PJ, Hollander IE, Kay AB. Prior health care utilization patterns and suicide among U.S. Army soldiers. Suicide Life Threat Behav. 2010;40(4):407-15.

20. Lee HC, Lin HC, Liu TC, Lin SY. Contact of mental and nonmental health care providers prior to suicide in Taiwan: a population-based study. Can J Psychiatry. 2008;53(6):377-83.

21. Britton PC, Ilgen MA, Rudd MD, Conner KR. Warning signs for suicide within a week of healthcare contact in Veteran decedents. Psychiatry Res. 2012.

22. Smith EG, Craig TJ, Ganoczy D, Walters HM, Valenstein M. Treatment of Veterans with depression who died by suicide: timing and quality of care at last Veterans Health Administration visit. J Clin Psychiatry. 2011;72(5):622-9.

23. Appleby L, Shaw J, Amos T, McDonnell R, Harris C, McCann K, et al. Suicide within 12 months of contact with mental health services: national clinical survey. BMJ. 1999;318(7193):1235-9.

24. Hornbrook MC, Hart G, Ellis JL, Bachman DJ, Ansell G, Greene SM, et al. Building a virtual cancer research organization. J Natl Cancer Inst Monogr. 2005;35:12-25.

25. Go AS, Magid DJ, Wells B, Sung SH, Cassidy-Bushrow AE, Greenlee RT, et al. The Cardiovascular Research Network: a new paradigm for cardiovascular quality and outcomes research. Circ Cardiovasc Qual Outcomes. 2008;1(2):138-47.

26. World Health Organization [WHO]. International Classification of Diseases, Tenth Revision. http://www.who.int/classifications/icd/en/; 2012.

27. National Center for Health Statistics. International Classification of Diseases, Ninth Revision, Clinical Modification. CDC: Atlanta; 2010.

28. While D, Bickley H, Roscoe A, Windfuhr K, Rahman S, Shaw J, et al. Implementation of mental health service recommendations in England and Wales and suicide rates, 1997-2006: a cross-sectional and beforeand-after observational study. Lancet. 2012;379(9820):1005-12.

29. Valenstein M, Kim HM, Ganoczy D, McCarthy JF, Zivin K, Austin KL et al. Higher-risk periods for suicide among VA patients receiving depression treatment: prioritizing suicide prevention efforts. J Affect Disord. 2009;112(1-3):50-8

30. Bruce ML, Ten Have TR, Reynolds CF III, Katz II, Schulberg HC, Mulsant BH, et al. Reducing suicidal ideation and depressive symptoms in depressed older primary care patients: a randomized controlled trial. JAMA. 2004;291(9):1081-91.

31. Valuck RJ, Anderson HO, Libby AM, Brandt E, Bryan C, Allen RR, et al. Enhancing electronic health record measurement of depression severity and suicide ideation: a Distributed Ambulatory Research in Therapeutics Network (DARTNet) study. J Am Board Fam Med. 2012;25(5):582-93.

32. Steinfield BI, Keyes JA. Electronic medical records in a multidisciplin ary health care setting: A clinical perspective. Prof Psychol: Res Pract. 2011;42(6):426-32.

33. Midboe AM, Lewis ET, Cronkite RC, Chambers D, Goldstein MK, Kerns RD, et al. Behavioral medicine perspectives on the design of health information technology to improve decision-making, guideline adherence, and care coordination in chronic pain management. Transl Behav Med. 2011;1(1):35-44.

34. Williams LK, Peterson EL, Wells K, Campbell J, Wang M, Chowdhry VK, et al. A cluster-randomized trial to provide clinicians inhaled corticosteroid adherence information for their patients with asthma. J Allergy Clin Immunol. 2010;126(2):225-31.

35. Ahmad FS, Tsang T. Diabetes prevention, health information technology, and meaningful use: challenges and opportunities. Am J Prev Med. 2013;44(4 Suppl 4):S357-63.

36. Posner K, Brown GK, Stanley B, Brent DA, Yershova KV, Oquendo MA, et al. The Columbia-Suicide Severity Rating Scale: initial validity and internal consistency findings from three multisite studies with adolescents and adults. Am J Psychiatry. 2011;168(12):1266-77.

37. Kroenke K, Spitzer RL, Williams JB. The PHQ-9: validity of a brief depression severity measure. J Gen Intern Med. 2001;16(9):606-13.

38. Bauer AM, Chan YF, Huang H, Vannoy S, Unutzer J. Characteristics, Management, and Depression Outcomes of Primary Care Patients Who Endorse Thoughts of Death or Suicide on the PHQ-9. J Gen Intern Med. 2012.

39. Cavanagh JT, Carson AJ, Sharpe M, Lawrie SM. Psychological autopsy studies of suicide: a systematic review. Psychol Med. 2003;33(3):395-405.

40. Wang PS, Berglund P, Olfson M, Pincus HA, Wells KB, Kessler RC. Failure and delay in initial treatment contact after first onset of mental disorders in the National Comorbidity Survey Replication. Arch Gen Psychiatry. 2005;62(6):603-13.

41. Reiss-Brennan B, Briot P, Cannon W, James B. Mental health integration: rethinking practitioner roles in the treatment of depression: the specialist, primary care physicians, and the practice nurse. Ethn Dis. 2006;16(2 Suppl 3):S3-43.

42. Solberg LI, Glasgow RE, Unutzer J, Jaeckels N, Oftedahl G, Beck A, et al. Partnership research: a practical trial design for evaluation of a natural experiment to improve depression care. Med Care. 2010;48(7):576-82

43. Madras BK, Compton WM, Avula D, Stegbauer T, Stein JB, Clark HW. Screening, brief interventions, referral to treatment (SBIRT) for illicit drug and alcohol use at multiple healthcare sites: comparison at intake and 6 months later. Drug Alcohol Depend. 2009;99(1-3):280-95.

44. Tai-Seale M, Bramson R, Drukker D, Hurwicz ML, Ory M, Tai-Seale T, et al. Understanding primary care physicians' propensity to assess elderly patients for depression using interaction and survey data. Med Care. 2005;43(12):1217-24.

45. United States Preventive Services Task Force. Screening for Depression: Recommendations and Rationale. http:// www.uspreventiveservicestaskforce.org/3rduspstf/depression/ depressrr.htm; 2002

46. Coffey CE. Building a system of perfect depression care in behaviora health. Jt Comm.J Qual Patient Saf. 2007;33(4):193-9.

47. Knox KL, Litts DA, Talcott GW, Feig JC, Caine ED. Risk of suicide and related adverse outcomes after exposure to a suicide prevention programme in the US Air Force: cohort study. BMJ. 2003;327(7428):1376.

48. Hooper LM, Epstein SA, Weinfurt KP, DeCoster J, Qu L, Hannah NJ. Predictors of primary care physicians' self-reported intention to conduct suicide risk assessments. J Behav Health Serv Res. 2012;39(2):103-15.

49. Graham RD, Rudd MD, Bryan CJ. Primary care providers' views regarding assessing and treating suicidal patients. Suicide Life Threat Behav. 2011;41(6):614-23.

50. Rutz W. Preventing suicide and premature death by education and treatment. J Affect Disord. 2001;62(1-2):123-9.

51. Denneson LM, Basham C, Dickinson KC, Crutchfield MC, Millet L, Shen $\mathbf{X}$, et al. Suicide risk assessment and content of VA health care contacts before suicide completion by veterans in Oregon. Psychiatr Serv. 2010;61(12):1192-7.

52. Rockett IR. Counting suicides and making suicide count as a public health problem. Crisis. 2010;31(5):227-30.

53. Timmermans $\mathbf{S}$. Suicide determination and the professional authority of medical examiners. Am Sociol Rev. 2005;70:311-33. 